\title{
Effect of erlotinib combined with cisplatin on IL-6 and IL-12 in mice with Lewis lung cancer
}

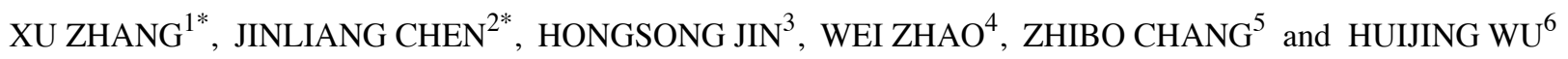 \\ ${ }^{1}$ Department of Thoracic Oncology, Sun Yat-sen University Cancer Center, Guangzhou, \\ Guangdong 510060; ${ }^{2}$ Department of Thoracic Oncology, Tianjin Medical University Cancer Institute and Hospital, \\ National Clinical Research Center for Cancer, Key Laboratory of Cancer Prevention and Therapy, Tianjin 300060; \\ ${ }^{3}$ Department of Oncology, The People's Hospital of Taizhou, Taizhou, Jiangsu 225300; ${ }^{4}$ Department of Thoracic Surgery, \\ The First Affiliated Hospital of Kunming Medical University, Kunming, Yunnan 650031; ${ }^{5}$ Department of Thoracic Surgery, \\ Second Affiliated Hospital of Zhejiang University, School of Medicine, Hangzhou, Zhejiang 310009; \\ ${ }^{6}$ Department of Medical Oncology, Radio-Chemotherapy Center, Hubei Cancer Hospital, Wuhan, Hubei 430079, P.R. China
}

Received June 6, 2019; Accepted January 14, 2020

DOI: 10.3892/ol.2020.11632

\begin{abstract}
Effect of erlotinib combined with cisplatin on tumor growth, interleukin-6 (IL-6) and interleukin-12 (IL-12) in mice with Lewis lung cancer (LLC) was investigated. Forty-four pure inbred SPF C57BL/6J mice were modeled for LLC and randomized into groups $\mathrm{A}, \mathrm{B}, \mathrm{C}$ and $\mathrm{D}$ ( $\mathrm{n}=11$ each group). Mice in group A were given normal saline, group B was given erlotinib, group $\mathrm{C}$ was given cisplatin injection and group D erlotinib combined with cisplatin. Tumor growth of the mice was observed and the tumor mass was measured. Serum IL-6 and IL-12 levels were measured by enzyme-linked immunosorbent assay (ELISA) 40 days later. At different time-points after medication, tumor volume in group $\mathrm{D}$ was significantly lower than that in groups $\mathrm{A}, \mathrm{B}$ and $\mathrm{C}(\mathrm{P}<0.05)$, and that in groups $\mathrm{B}$ and $\mathrm{C}$ was significantly lower than that in group $\mathrm{A}$ $(\mathrm{P}<0.05)$, whereas there was no significant difference between groups $\mathrm{B}$ and $\mathrm{C}(\mathrm{P}>0.05)$. Tumor mass in groups $\mathrm{B}, \mathrm{C}$ and $\mathrm{D}$ was significantly lower than that in group $\mathrm{A}(\mathrm{P}<0.05)$, and that in group $\mathrm{D}$ was significantly lower than that in groups $\mathrm{B}$ and $\mathrm{C}(\mathrm{P}<0.05)$, whereas there was no significant difference between groups $\mathrm{B}$ and $\mathrm{C}(\mathrm{P}>0.05)$. Compared with groups $\mathrm{B}$ and $\mathrm{C}$, mice in group $\mathrm{D}$ had significantly lower IL-6 level
\end{abstract}

Correspondence to: Dr Zhibo Chang, Department of Thoracic Surgery, Second Affiliated Hospital of Zhejiang University, School of Medicine, 88 Jiefang Road, Hangzhou, Zhejiang 310009, P.R. China

E-mail: bzpc41@163.com

Dr Huijing Wu, Department of Medical Oncology, RadioChemotherapy Center, Hubei Cancer Hospital, 116 Zhuodaoquan South Road, Wuhan, Hubei 430079, P.R. China

E-mail: 2313069@zju.edu.cn

${ }^{*}$ Contributed equally

Key words: erlotinib, cisplatin, lung cancer, IL-6, IL-12
$(\mathrm{P}<0.05)$, but significantly higher IL-12 level $(\mathrm{P}<0.05)$. There was no significant difference in IL-6 and IL-12 levels between groups $\mathrm{B}$ and $\mathrm{C}(\mathrm{P}>0.05)$. In conclusion, erlotinib combined with cisplatin can inhibit the tumor growth of mice with LLC, and inhibition of IL-6 level and upregulation of IL-12 level may be one of its therapeutic mechanisms.

\section{Introduction}

As a common malignant tumor threatening human life and health, lung cancer has increasing morbidity and mortality rates (1). Approximately $85 \%$ of patients with the disease are patients with non-small cell lung cancer (NSCLC). Early lung cancer mostly treated by surgery has no obvious signs and symptoms, so the patients diagnosed have been in the middle and advanced stages when the tumor tissue has metastasized. That is to say, the patients lose the best surgical treatment time and have a low overall survival rate $(2,3)$. Clinically, lung cancer has been treated by platinum-based chemotherapy. Although dose-limited platinum drugs cause toxic and side effects such as nephrotoxicity and neurotoxicity, cisplatin improves the overall survival of patients with lung cancer metastasis (4). With the development of molecular biology, targeted therapy is gradually used for the treatment of lung cancer $(5,6)$. Epidermal growth factor receptor (EGFR) mutations are common drivers of lung cancer, and EGFR-tyrosine kinase inhibitors (TKIs) are considered as the best choice for the first-line treatment of advanced or recurrent non-squamous NSCLC carrying activating EGFR mutations (7). EGFR-TKIs are more effective for patients with EGFR mutant lung cancer than platinum-based chemotherapy (8). Erlotinib as a kind of EGFR-TKIs, is clinically effective for the treatment of NSCLC (9). According to Korytowsky et al (10), there is no significant difference in efficacy between erlotinib and chemotherapy (docetaxel or pemetrexed) for patients with advanced NSCLC who have received platinum-based chemotherapy for no more than 4 cycles and have disease progression during or after chemotherapy. 
In previous treatment, tumor cells were given high level of consideration, while the influence of tumor microenvironment on the efficacy was ignored (11). Interleukin-6 (IL-6), a cytokine that exists in tumor microenvironment, is closely related to cancer cell proliferation, angiogenesis and metastasis (12). IL-12 is one of the most effective cytokines for mediating antitumor activity and has a pleiotropic effect on immune cells forming tumor microenvironment. As a therapeutic target for tumors, it establishes a link between innate and adaptive immunities and plays a key role in shaping antitumor or tumor immunity (13).

Previous studies have shown obvious benefits of erlotinib and cisplatin in advanced lung cancer (14), but few studies exist on the specific application of erlotinib combined with cisplatin and its effects on IL-6 and IL-12. Lewis lung cancer mouse model is one of the tumor models frequently used in studies. As a common model for studying drug treatment of lung cancer, it is easy to model and has high tumor formation rate (15). Therefore, a mouse model of lung cancer was established in this study to explore the effects of erlotinib combined with cisplatin on the tumor growth, IL-6 and IL-12 of mice with Lewis lung cancer (LLC).

\section{Materials and methods}

Animals and cells. Forty-four pure inbred SPF C57BL/6J mice [Shanghai SLAC Laboratory Animal Co., Ltd., license no. SCXK (2003-0003)], aged 6-8 weeks with a body weight of $20.13 \pm 2.16 \mathrm{~g}$, were fed with SPF granular chow in well ventilated clean facility. They have free access to water and food. Indoor humidity was $45-64 \%$ and indoor temperature was $20-24^{\circ} \mathrm{C}$, with 12 -h light $(500 \mathrm{~lx}) / 12$-h dark (0 lx). This experiment was carried out 1 week after acclimatization and was approved by the Ethics Committee of the Hospital, with the process following Guide for the Care and Use of Laboratory Animals (16,17). LLC cell line of the mice was introduced by Beina Chuanglian Biotechnology Research Institute (item no. ATCCCRL-1642) and stored in liquid nitrogen.

Cell culture and preparation of animal models. LLC cells were inoculated into a culture dish, added with RPMI-1640 medium containing $10 \%$ fetal bovine serum (both from Gibco BRL) and 1\% mycillin/streptomycin, and then cultured in an incubator (Thermo Electron Corporation) at $37^{\circ} \mathrm{C}$ with $5 \% \mathrm{CO}_{2}$. The culture fluid was changed once/2 days, and the LLC cell line was digested with $2.5 \%$ pancreatin and then passaged. Cells in logarithmic phase were taken to prepare a suspension with a cell concentration of $2.80 \times 10^{7} \mathrm{ml}^{-1}$ for subsequent experiments.

Modeling, grouping and medication. The mice were fixed on the operating console for routine skin disinfection then $0.2 \mathrm{ml}$ ( $2 \times 10^{6}$ living cells) of the LLC cell suspension was subcutaneously injected into the right axilla of mice with a $1 \mathrm{ml}$ syringe, during aseptic operation. The tumor formed around the 8 th day and then grew to $\sim 8 \mathrm{~mm}$. At that time, 44 mice were randomized into groups $\mathrm{A}, \mathrm{B}, \mathrm{C}$ and $\mathrm{D}$. Mice in group A were given $30 \mathrm{mg} / \mathrm{kg}$ of normal saline, group B was given $30 \mathrm{mg} / \mathrm{kg}$ of erlotinib (Roche Medical Electronics), group C was given
$3 \mathrm{mg} / \mathrm{kg}$ of cisplatin injection (Qilu Pharmaceutical Co., Ltd., batch no. ALA1206023) and group D erlotinib (30 mg/kg) combined with cisplatin $(3 \mathrm{mg} / \mathrm{kg}$ ). From the 2 nd day after modeling, the drugs were intraperitoneally injected once daily for 21 consecutive days.

Observational indexes and methods. The longest diameter (a) and the shortest diameter (b) of the tumor were measured with vernier calipers at 1 day, 5 days, 9 days, 13 days, 17 days and 21 days after medication. The tumor volume was estimated with reference to $\mathrm{V}=\mathrm{ab}^{2} / 2$ (18), and the tumor growth curve was plotted.

Forty days later, the mice were sacrificed through Cervical dislocation, with the eyeballs enucleated. The eyeballs were removed and $0.5 \mathrm{ml}$ of blood was taken with the EP tube. The serum was separated by centrifugation at $1,500 \mathrm{x}$ at $4^{\circ} \mathrm{C}$ for 10 min. Upper serum $(50 \mu \mathrm{l})$ was collected and stored in a refrigerator at $-80^{\circ} \mathrm{C}$. The tumor was excised and measured for mass (average tumor mass in group A - average tumor mass in each group after medication)/average tumor mass in group $\mathrm{A}$ $\mathrm{x} 100 \%=$ tumor inhibition rate (TIR).

Serum IL-6 and IL-12 levels were detected by enzymelinked immunosorbent assay (ELISA) according to the instructions of mouse IL-6 and IL-12 ELISA kits (Shanghai Hengfei Biotechnology Co., Ltd., CSB-E04639m-1, CSB-E07360m-1). All samples and reagents were taken out in advance to balance with room temperature. The ELISA plate was washed twice with $300 \mu$ l of washing liquid, and discarded, the wells were dried with absorbent paper. A well for the sample to be tested, a standard well and a blank well were set up, in which $50 \mu$ l of the sample, standard substance and sample diluent was respectively added, and then $50 \mu \mathrm{l}$ of biotin-labeled antibody was added. The plate was sealed with a microplate sealer and incubated at $37^{\circ} \mathrm{C}$ for $1 \mathrm{~h}$. After the liquid was discarded, each well was added with $300 \mu \mathrm{l}$ of the washing liquid to wash the plate 5 times, and the wells were dried each time after the washing. Each well was added with $100 \mu \mathrm{l}$ of streptavidin, and then the plate was sealed with a microplate sealer and incubated at $37^{\circ} \mathrm{C}$ for $1 \mathrm{~h}$. Each well was added with $300 \mu 1$ of the washing liquid to wash the plate 5 times, and the wells were dried each time after the washing. Each well was added with $50 \mu \mathrm{l}$ of $\mathrm{A}$ and $50 \mu \mathrm{l}$ of B working solutions, and then incubated in dark at room temperature for $20 \mathrm{~min}$. After that, $100 \mu \mathrm{l}$ of stop solution was added to each well. OD values of each well were detected at $450 \mathrm{~nm}$ using a 680 fully automatic microplate reader (Bio-Rad), to calculate IL-6 and IL-12 levels.

Statistical methods. SPSS 18.0 (IBM Corp.) was used for statistical analysis, GraphPad Prism 7 for plotting figures. Count data were expressed by the number of cases/percentage (n/\%), and Chi-square test was used for comparison of the count data between groups. Measurement data were expressed by mean \pm standard deviation (mean $\pm \mathrm{SD}$ ), and one-way analysis of variance (ANOVA) was used for comparison of mean between multiple groups. After that, Dunnett t-test was used for pairwise comparison, repeated measures ANOVA for comparison of different time-points, Bonferroni for pairwise comparison between different time-points within groups. $\mathrm{P}<0.05$ indicates a statistically significant difference. 
Table I. Comparison of general conditions $[\mathrm{n}(\%)] /($ mean $\pm \mathrm{SD})$.

\begin{tabular}{lcccccc}
\hline Categories & Group A $(\mathrm{n}=11)$ & Group B $(\mathrm{n}=11)$ & Group C $(\mathrm{n}=11)$ & Group D $(\mathrm{n}=11)$ & $\mathrm{F} / \chi^{2}$ value & P-value \\
\hline Sex & & & & & 0.786 & 0.853 \\
Male $(\%)$ & $7(63.64)$ & $8(72.73)$ & $7(63.64)$ & $6(54.55)$ & & \\
Female $(\%)$ & $4(36.36)$ & $3(27.27)$ & $4(36.36)$ & $5(45.45)$ & & \\
Age (weeks) & $7.02 \pm 0.58$ & $6.94 \pm 0.46$ & $7.12 \pm 0.51$ & $6.85 \pm 0.63$ & 0.483 & 0.696 \\
Body weight $(\mathrm{g})$ & $20.13 \pm 2.16$ & $21.08 \pm 1.93$ & $20.47 \pm 2.09$ & $20.54 \pm 2.12$ & 0.394 & 0.758 \\
Indoor humidity $(\%)$ & $50.18 \pm 2.93$ & $49.76 \pm 3.67$ & $50.26 \pm 3.52$ & $51.64 \pm 3.46$ & 0.727 & 0.542 \\
Indoor temperature $\left({ }^{\circ} \mathrm{C}\right)$ & $22.05 \pm 1.24$ & $22.67 \pm 0.94$ & $22.38 \pm 1.05$ & $22.03 \pm 1.27$ & 0.792 & 0.505 \\
\hline
\end{tabular}

Table II. Comparison of tumor mass and TIR (mean $\pm \mathrm{SD}$ ).

\begin{tabular}{lccc}
\hline Groups & $\mathrm{n}$ & Tumor mass/g & TIR $(\%)$ \\
\hline Group A & 11 & $5.57 \pm 0.27$ & - \\
Group B & 11 & $3.42 \pm 0.53^{\mathrm{a}}$ & 38.60 \\
Group C & 11 & $3.37 \pm 0.24^{\mathrm{a}}$ & 44.88 \\
Group D & 11 & $1.89 \pm 0.13^{\mathrm{a}, \mathrm{b}}$ & 66.07 \\
F value & - & 242.000 & - \\
P-value & - & $<0.001$ & -
\end{tabular}

${ }^{\mathrm{a}} \mathrm{P}<0.05$ compared with group $\mathrm{A} ;{ }^{\mathrm{b}} \mathrm{P}<0.05$ compared with groups $\mathrm{B}$ and $\mathrm{C}$. TIR, tumor inhibition rate.

\section{Results}

Comparison of general conditions. There were no statistically significant differences between groups A, B, C and D with respect to sex, age, body weight, indoor temperature and indoor humidity $(\mathrm{P}>0.05)$ (Table I).

Comparison of tumor volume. According to the tumor growth curve, the tumor volume of mice in the four groups increased with time, and the growth rate of group A was the fastest, followed by groups C, B and D. According to repeated measures ANOVA, there was a statistically significant difference in tumor volume between the four groups after medication $(\mathrm{P}<0.05)$. At different time-points after medication, tumor volume in group $\mathrm{D}$ was significantly lower than that in groups $\mathrm{A}, \mathrm{B}$ and $\mathrm{C}(\mathrm{P}<0.05)$, and that in groups $\mathrm{B}$ and $\mathrm{C}$ was significantly lower than that in group $A(P<0.05)$, whereas there was no significant difference between groups $\mathrm{B}$ and $\mathrm{C}$ (P>0.05) (Fig. 1).

Comparison of tumor mass. There was a statistically significant difference in tumor mass between the four groups $(\mathrm{P}<0.05)$. Tumor mass in groups B, C and D was significantly lower than that in group $A(P<0.05)$, and that in group $D$ was significantly lower than that in groups $\mathrm{B}$ and $\mathrm{C}(\mathrm{P}<0.05)$, whereas there was no significant difference between groups $\mathrm{B}$ and $\mathrm{C}(\mathrm{P}>0.05)$ (Table II and Fig. 2).

Comparison of IL- 6 and IL-12 levels after treatment. There were statistically significant differences in IL-6 and IL-12
Table III. Comparison of IL-6 and IL-12 levels (mean \pm SD).

\begin{tabular}{lccc}
\hline Groups & $\mathrm{n}$ & $\mathrm{IL}-6(\mathrm{ng} / \mathrm{ml})$ & $\mathrm{IL}-12(\mathrm{ng} / \mathrm{ml})$ \\
\hline Group A & 11 & $3.19 \pm 0.35$ & $4.73 \pm 0.54$ \\
Group B & 11 & $2.59 \pm 0.37^{\mathrm{a}}$ & $5.39 \pm 0.66^{\mathrm{a}}$ \\
Group C & 11 & $2.51 \pm 0.43^{\mathrm{a}}$ & $5.34 \pm 0.62^{\mathrm{a}}$ \\
Group D & 11 & $2.08 \pm 0.29^{\mathrm{a}, \mathrm{b}}$ & $5.94 \pm 0.41^{\mathrm{a}, \mathrm{b}}$ \\
F value & - & 17.390 & 8.415 \\
P-value & - & $<0.001$ & $<0.001$ \\
\hline
\end{tabular}

${ }^{\text {a }}<0.05$ compared with group $\mathrm{A} ;{ }^{\mathrm{b}} \mathrm{P}<0.05$ compared with groups $\mathrm{B}$ and C. IL, interleukin.

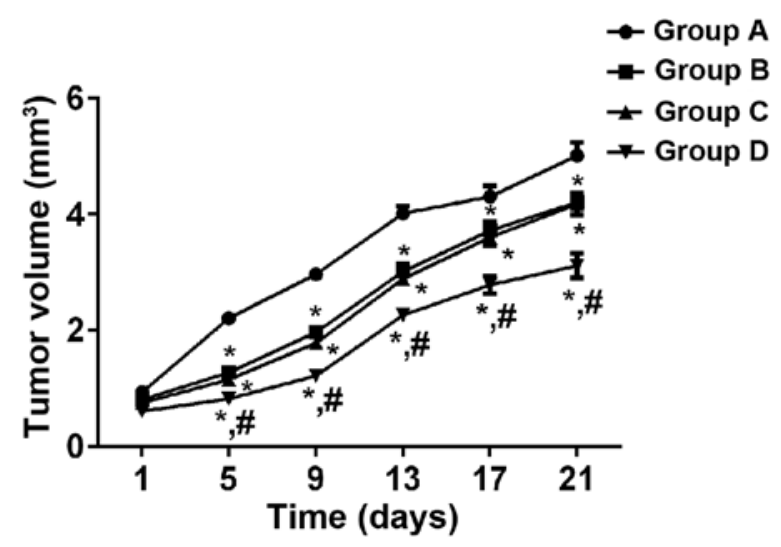

Figure 1. Comparison of tumor volume. According to repeated measures ANOVA, there was a statistically significant difference in tumor volume between the four groups after medication $(\mathrm{P}<0.05)$. At different time-points after medication, tumor volume in group $\mathrm{D}$ was significantly lower than that in groups $\mathrm{A}, \mathrm{B}$ and $\mathrm{C}(\mathrm{P}<0.05)$, and that in groups $\mathrm{B}$ and $\mathrm{C}$ was significantly lower than that in group $A(P<0.05)$, whereas there was no significant difference between groups $\mathrm{B}$ and $\mathrm{C}(\mathrm{P}>0.05) .{ }^{*} \mathrm{P}<0.05$ compared with group $\mathrm{A}$ at the same time-point; ${ }^{\#} \mathrm{P}<0.05$ compared with groups $\mathrm{B}$ and $\mathrm{C}$ at the same time-point.

levels between the four groups $(\mathrm{P}<0.05)$. Compared with group $\mathrm{A}$, mice in groups $\mathrm{B}, \mathrm{C}$ and $\mathrm{D}$ had significantly lower IL-6 levels $(\mathrm{P}<0.05)$, but significantly higher IL-12 levels $(\mathrm{P}<0.05)$. Compared with groups $\mathrm{B}$ and $\mathrm{C}$, mice in group $\mathrm{D}$ had significantly lower IL-6 level $(\mathrm{P}<0.05)$, but significantly higher IL-12 level $(\mathrm{P}<0.05)$. There were no significant differences in IL-6 and IL-12 levels between groups B and C $(\mathrm{P}>0.05)$ (Table III and Fig. 3). 


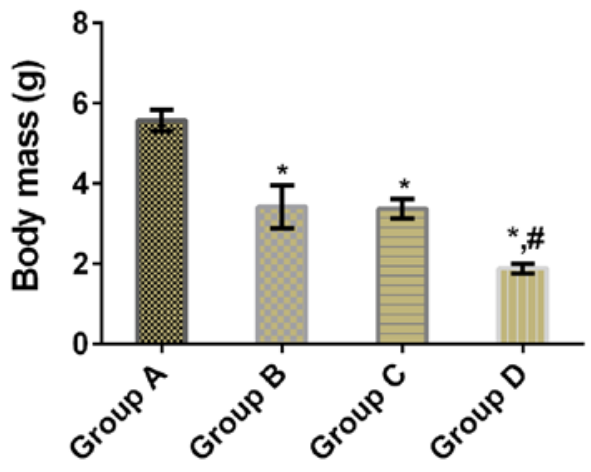

Figure 2. Comparison of tumor mass. Tumor mass in groups B, C and D was significantly lower than that in group $\mathrm{A}(\mathrm{P}<0.05)$, and that in group $\mathrm{D}$ was significantly lower than that in groups $\mathrm{B}$ and $\mathrm{C}(\mathrm{P}<0.05)$, whereas there was no significant difference between groups $\mathrm{B}$ and $\mathrm{C}(\mathrm{P}>0.05) .{ }^{*} \mathrm{P}<0.05$ compared with group $\mathrm{A} ;{ }^{~} \mathrm{P}<0.05$ compared with groups $\mathrm{B}$ and $\mathrm{C}$.

\section{Discussion}

Most patients with lung cancer are in the advanced stage when diagnosed. Those who undergo chemotherapy and radiotherapy for the treatment of unresectable advanced lung cancer have poor median progression-free survival time and 5-year overall survival time (19). Patients with advanced lung cancer are mostly treated by platinum drugs, but some of the patients have poor tolerance and therapeutic effects. Therefore, lung cancer has no cure although chemotherapeutics are continuously updated (20).

First-line treatment decisions for advanced lung cancer are currently based on sensitive EGFR mutations (21). In recent years, EGFR-TKIs represented by erlotinib, which specifically inhibits EGFR signaling pathway and further inhibits tumor growth are increasingly valued in the comprehensive treatment of lung cancer (22). According to Scagliotti et al (23), erlotinib combined with gefitinib is a tolerable regimen and has better clinical efficacy than erlotinib alone in chemotherapy for patients with EGFR-mutant NSCLC. Therefore, the combination of erlotinib and other drugs is effective for patients with advanced lung cancer. It has been shown that erlotinib-cisplatin combination is effective for erlotinib-resistant cancer by targeting (downregulating) Atg3-mediated autophagy and inducing apoptotic cell death (24). However, scarce research exists on the effects of erlotinib combined with cisplatin for lung cancer in vivo. Lewis lung cancer is a commonly used model for studying drug therapy for lung cancer, so Lewis lung cancer mice were used in this study. Tumor volume in group D was significantly lower than that in groups A, B and C at different time-points after medication, and tumor mass was significantly lower than that in groups $\mathrm{A}, \mathrm{B}$ and $\mathrm{C}$, suggesting that erlotinib combined with cisplatin significantly inhibits the tumor growth of mice with lung cancer. Therefore, erlotinib combined with cisplatin may become a new therapeutic regimen for lung cancer.

IL-6 is a main cytokine in tumor microenvironment, and its high level shows the correlation of inflammations with cancers. It promotes tumorigenesis through regulating markers and signal transduction pathways (including apoptosis, survival, proliferation, angiogenesis, invasion and metastasis) of cancers (25). As a cytokine that stimulates cellular immunity, IL-12 exerts effective antitumor activity through immune stimulation and antiangiogenic mechanisms, and promotes rapid reversal of
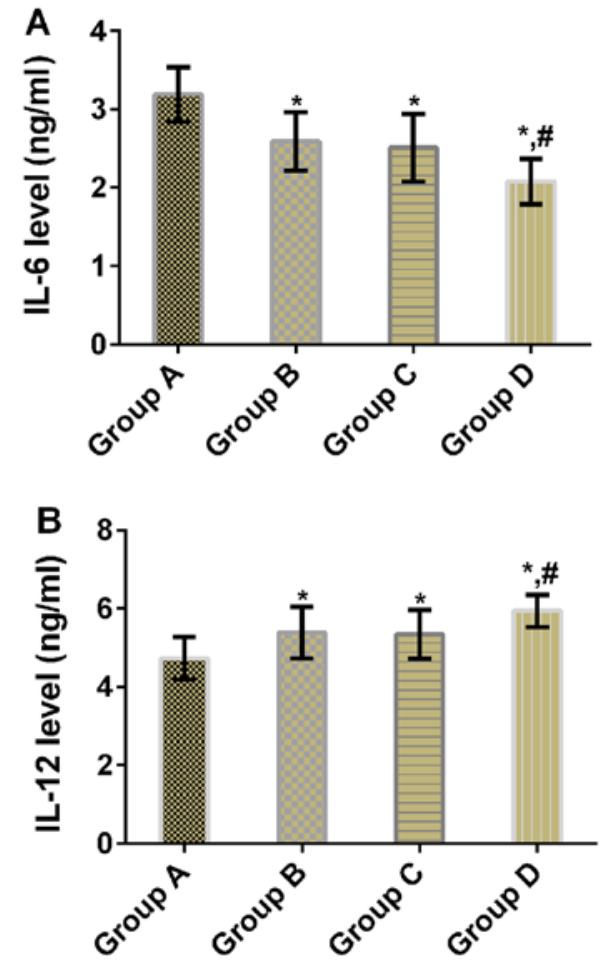

Figure 3. Comparison of IL-6 and IL-12 levels after treatment. ELISA was used to detect IL-6 level (A) and IL-12 level (B). * P $<0.05$ compared with group $\mathrm{A} ;{ }^{\text {" }} \mathrm{P}<0.05$ compared with groups $\mathrm{B}$ and $\mathrm{C}$. ELISA, enzyme-linked immunosorbent assay; IL, interleukin.

immunosuppression in tumor microenvironment (26). In a study by Caetano et al (27), IL-6 was used as a therapeutic target for tumors, and its blocking not only directly inhibited tumor cells, but also redirected the lung microenvironment to antitumor phenotypes through changing the ratio of tumor-promoting to antitumor immune cells. According to $\mathrm{Li}$ et al (28), the antitumor activity of IL-12 increases the immunoregulation of cytokines, inhibits the growth of human lung adenocarcinoma and acts on normal bronchial epithelial cells near tumors. In this study, mice in group D had significantly lower IL-6 level but significantly higher IL-12 level, indicating that inhibition of IL-6 level and upregulation of IL-12 level through improvement of the microenvironment may be a therapeutic mechanism of erlotinib combined with cisplatin for lung cancer. However, the specific regulatory mechanism remains to be further studied.

This study confirmed the inhibitory effect of erlotinib combined with cisplatin on the tumor growth of mice with lung cancer, and preliminarily discussed its therapeutic mechanism.

In conclusion, erlotinib combined with cisplatin can inhibit the tumor growth of mice with LLC, and inhibition of IL-6 level and upregulation of IL-12 level may be one of its therapeutic mechanisms.

\section{Acknowledgements}

Not applicable.

\section{Funding}

This study was supported by the Science and Technology Plan Projects of Guangdong Province of China(no.2013B021800163). 


\section{Availability of data and materials}

The datasets used and/or analyzed during the present study are available from the corresponding author on reasonable request.

\section{Authors' contributions}

XZ conceived the study and wrote the manuscript. JC and HJ were responsible for ELISA. WZ, ZC and HW contributed to analysis of observation indexes. The final version was read and adopted by all the authors. All authors read and approved the final manuscript.

\section{Ethics approval and consent to participate}

The study was approved by the Ethics Committee of the Second Affiliated Hospital of Zhejiang University (Hangzhou, China).

\section{Patient consent for publication}

Not applicable.

\section{Competing interests}

The authors declare that they have no competing interests.

\section{References}

1. Cetta F, Renieri A and Frullanti E: Germline mutations in lung cancer and personalized medicine. Fam Cancer 17: 429-430, 2018.

2. Minguet J, Smith KH and Bramlage P: Targeted therapies for treatment of non-small cell lung cancer - Recent advances and future perspectives. Int J Cancer 138: 2549-2561, 2016.

3. Rittmeyer A, Barlesi F, Waterkamp D, Park K, Ciardiello F von Pawel J, Gadgeel SM, Hida T, Kowalski DM, Dols MC, et al; OAK Study Group: Atezolizumab versus docetaxel in patients with previously treated non-small-cell lung cancer (OAK): A phase 3, open-label, multicentre randomised controlled trial. Lancet 389: 255-265, 2017.

4. Kaplan JA, Liu R, Freedman JD, Padera R, Schwartz J, Colson YL and Grinstaff MW: Prevention of lung cancer recurrence using cisplatin-loaded superhydrophobic nanofiber meshes. Biomaterials 76: 273-281, 2016.

5. Carbone DP, Reck M, Paz-Ares L, Creelan B, Horn L, Steins M, Felip E, van den Heuvel MM, Ciuleanu TE, Badin F, et al CheckMate 026 Investigators: First-line nivolumab in stage IV or recurrent non-small-cell lung cancer. N Engl J Med 376: 2415-2426, 2017.

6. Liu H and Song Y: MDT is still important in the treatment of early stage lung cancer. J Thorac Dis 10 (Suppl 33): S3984-S3985, 2018

7. Haratani K, Hayashi H, Tanaka T, Kaneda H, Togashi Y, Sakai K, Hayashi K, Tomida S, Chiba Y, Yonesaka K, et al: Tumor immune microenvironment and nivolumab efficacy in EGFR mutation-positive non-small-cell lung cancer based on T790M status after disease progression during EGFR-TKI treatment. Ann Oncol 28: 1532-1539, 2017.

8. Fukuoka M, Wu YL, Thongprasert S, Sunpaweravong P, Leong SS, Sriuranpong V, Chao TY, Nakagawa K, Chu DT, Saijo N, et al: Biomarker analyses and final overall survival results from a phase III, randomized, open-label, first-line study of gefitinib versus carboplatin/paclitaxel in clinically selected patients with advanced non-small-cell lung cancer in Asia (IPASS). J Clin Oncol 29: 2866-2874, 2011.

9. Lu S, Yu Y and Yang Y: Retrospect and prospect for lung cancer in China: Clinical advances ofimmune checkpoint inhibitors. Oncologist 24 (Suppl 1): S21-S30, 2019.

10. Korytowsky B, Radtchenko J, Nwokeji ED, Tuell KW, Kish JK and Feinberg BA: Understanding total cost of care in advanced non-small cell lung cancer pre- and postapproval of immuno-oncology therapies. Am J Manag Care 24 (Suppl 20): S439-S447, 2018.
11. Yang JD, Nakamura I and Roberts LR: The tumor microenvironment in hepatocellular carcinoma: Current status and therapeutic targets. Semin Cancer Biol 21: 35-43, 2011.

12. Bharti R, Dey G and Mandal M: Cancer development, chemoresistance, epithelial to mesenchymal transition and stem cells: A snapshot of IL-6 mediated involvement. Cancer Lett 375: 51-61, 2016.

13. Tugues S, Burkhard SH, Ohs I, Vrohlings M, Nussbaum K, Vom Berg J,Kulig P and Becher B: New insights into IL-12-mediated tumor suppression. Cell Death Differ 22: 237-246, 2015.

14. Garon EB, Siegfried JM, Stabile LP, Young PA, MarquezGarban DC, Park DJ, Patel R, Hu EH, Sadeghi S, Parikh RJ, et al: Randomized phase II study of fulvestrant and erlotinib compared with erlotinib alone in patients with advanced or metastatic non-small cell lung cancer. Lung Cancer 123: 91-98, 2018.

15. Doki Y, Murakami K, Yamaura T, Sugiyama S, Misaki T and Saiki I: Mediastinal lymph node metastasis model by orthotopic intrapulmonary implantation of Lewis lung carcinoma cells in mice. Br J Cancer 79: 1121-1126, 1999.

16. Ogden BE, Pang William W, Agui T and Lee BH: Laboratory animal laws, regulations, guidelines and standards in China Mainland, Japan, and Korea. ILAR J 57: 301-311, 2016.

17. Karachaliou N, Fernandez-Bruno M, Bracht JWP and Rosell R: Challenges and unanswered questions for the next decade of immune-oncology research in NSCLC. Transl Lung Cancer Res 7: 691-702, 2018.

18. Berland L, Heeke S, Humbert O, Macocco A, Long-Mira E, Lassalle S, Lespinet-Fabre V, Lalvée S, Bordone O, Cohen C, et al: Current views on tumor mutational burden in patients with non-small cell lung cancer treated by immune checkpoint inhibitors. J Thorac Dis 11 (Suppl 1): S71-S80, 2019.

19. Kim YH: Durvalumab after chemoradiotherapy in Stage III non-small-cell lung cancer. N Engl J Med 380: 989-990, 2019.

20. Sasaki T, Seto T, Yamanaka T, Kunitake N, Shimizu J, Kodaira T, Nishio M, Kozuka T, Takahashi T, Harada H, et al: A randomised phase II trial of S-1 plus cisplatin versus vinorelbine plus cisplatin with concurrent thoracic radiotherapy for unresectable, locally advanced non-small cell lung cancer: WJOG5008L. Br J Cancer 119: 675-682, 2018.

21. Reck M, Rodríguez-Abreu D, Robinson AG, Hui R, Csőszi T, Fülöp A, Gottfried M, Peled N, Tafreshi A, Cuffe S, et al; KEYNOTE-024 Investigators: Pembrolizumab versus chemotherapy for PD-L1-positive non-small-cell lung cancer. N Engl J Med 375: 1823-1833, 2016.

22. Furugaki K, Fukumura J, Iwai T, Yorozu K, Kurasawa M, Yanagisawa M, Moriya Y, Yamamoto K, Suda K, Mizuuchi H, et al: Impact of bevacizumab in combination with erlotinib on EGFR-mutated non-small cell lung cancer xenograft models with T790M mutation or MET amplification. Int J Cancer 138: 1024-1032, 2016.

23. Scagliotti GV, Shuster D, Orlov S, von Pawel J, Shepherd FA, Ross JS, Wang Q, Schwartz B and Akerley W: Tivantinib in combination with erlotinib versus erlotinib alone for EGFR-Mutant NSCLC: An exploratory analysis of the phase 3 MARQUEE study. J Thorac Oncol 13: 849-854, 2018.

24. Lee JG and Wu R: Combination erlotinib-cisplatin and Atg3-mediated autophagy in erlotinib resistant lung cancer. PLoS One 7: e48532, 2012.

25. Kumari N, Dwarakanath BS, Das A and Bhatt AN: Role of interleukin-6 in cancer progression and therapeutic resistance. Tumour Biol 37: 11553-11572, 2016.

26. Li Q, Virtuoso LP, Anderson CD and Egilmez NK: Regulatory rebound in IL-12-treated tumors is driven by uncommitted peripheral regulatory T cells. J Immunol Volume?: 1293-1300, 2015.

27. Caetano MS, Zhang H, Cumpian AM, Gong L, Unver N, Ostrin EJ, Daliri S, Chang SH, Ochoa CE, Hanash S, et al: IL-6 blockade reprograms the lung tumor microenvironment to limit the development and progression of K-ras mutant lung cancer. Cancer Res 76: 3189-3199, 2016.

28. Li G and Lu B: Patients come first - the direction of lung cancer treatment. J Thorac Dis 10: E714-E715, 2018.

This work is licensed under a Creative Commons Attribution-NonCommercial-NoDerivatives 4.0 International (CC BY-NC-ND 4.0) License. 